
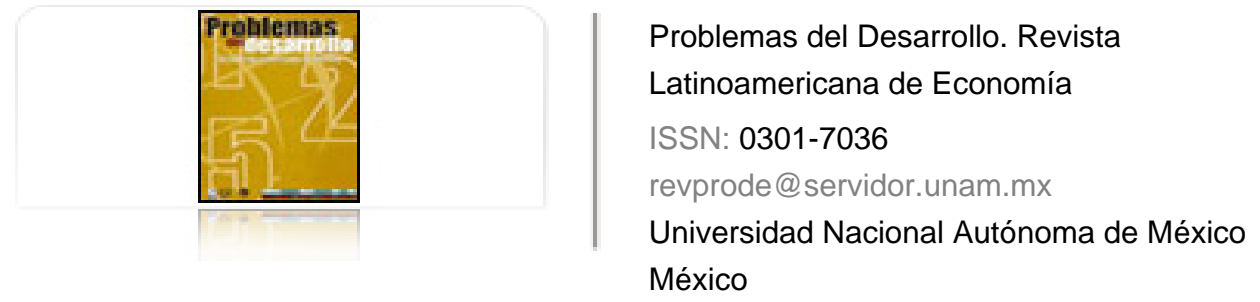

Palma, Pedro A.

Riesgos y consecuencias de las economías rentistas. El caso de Venezuela Problemas del Desarrollo. Revista Latinoamericana de Economía, vol. 42, núm. 165, abril-junio, 2011, pp. 35-59

Universidad Nacional Autónoma de México

Distrito Federal, México

Disponible en: http://www.redalyc.org/articulo.oa?id=11819780003

Cómo citar el artículo

- Número completo

- Más información del artículo

Página de la revista en redalyc.org

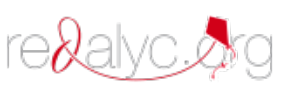

Sistema de Información Científica

Red de Revistas Científicas de América Latina, el Caribe, España y Portugal Proyecto académico sin fines de lucro, desarrollado bajo la iniciativa de acceso abierto 


\title{
RIESGOS Y CONSECUENCIAS DE LAS ECONOMÍAS RENTISTAS El CASO de VenEZUELA
}

\begin{abstract}
Pedro A. Palma*
Fecha de recepción: 22 de noviembre de 2010. Fecha de aceptación: 16 de febrero de 2011.
\end{abstract}

\begin{abstract}
RESUMEN
Las economías rentistas, es decir aquellas que dependen de la renta generada por una actividad económica, generalmente de la exportación de algún producto básico como el petróleo, no pueden experimentar un proceso de desarrollo sostenible, ya que al depender de actividades económicas cambiantes y volátiles que están sujetas a realidades externas fuera de su control, se transforman en economías vulnerables y cambiantes. Tradicionalmente, aplican políticas económicas procíclicas que generan bonanza en los periodos de altos precios del producto que exportan, pero recesión, empobrecimiento e inflación en los periodos de bajos precios. En ellas se aprecia notablemente la moneda en los años de bonanza, para luego sufrir masivas devaluaciones con efectos devastadores. Para corregir esa vulnerabilidad es necesario evitar la implementación de políticas procíclicas, crear fondos de estabilización, diversificar la economía y aplicar políticas cambiarias dinámicas.
\end{abstract}

Palabras clave: economía rentista, enfermedad holandesa, vulnerabilidad económica, fondos de estabilización, diversificación económica.

\section{RISKS AND CONSEQUENCES OF RENTALIST ECONOMIES The Case of Venezuela}

\begin{abstract}
Rentalist economies -i.e. economies that depend on the rents generated by economic activity, generally the export of some basic product such as oil -are unable to experience a process of sustainable development, because in depending on changing and volatile economic activities subjects them to external realities beyond their control, transforming them into vulnerable and changeable economies. Traditionally, they apply pro-cyclical economic policies that generate bonanzas during periods of high prices for the product they export, but recession, impoverishment and inflation during periods of low prices. Thus, in the bonanza years, their currencies appreciate significantly, but when prices are low they suffer sharp depreciation with devastating effects.

Key words: rentalist economy, Dutch Disease, economic vulnerability, stabilization funds, economic diversification.

* Presidente de la Academia Nacional de Ciencias Económicas de Venezuela. Correo electrónico:palma.pa1@gmail.com
\end{abstract}




\section{RISQUES ET CONSÉQUENCES DES ÉCONOMIES RENTIÈRES : LE CAS DU VÉNÉZUELA \\ Résumé}

Les économies rentières, c'est-à-dire celles qui dépendent de la rente générée par une activité économique, généralement l'exportation d'un produit de base comme le pétrole, ne peuvent pas connaître un processus de développement durable, étant donné que du fait de leur dépendance vis-à-vis d'activités économiques changeantes et volatiles qui sont sujettes à des réalités externes hors de leur contrôle, elles deviennent des économies vulnérables et changeantes. Traditionnellement, elles sont soumises à des politiques économiques pro-cycliques qui sont sources de prospérité dans les périodes où le prix du produit exporté est élevé, mais qui génèrent récession, appauvrissement et inflation dans les périodes où son prix est bas. La valeur de leurs monnaies augmente considérablement pendant les années de prospérité mais pâtit ensuite de dévaluations massives dont les effets sont dévastateurs.

Mots clés : économie rentière, maladie hollandaise, vulnérabilité économique, fonds de stabilisation, diversification économique.

\section{RISCOS E CONSEQUÊNCIAS DAS ECONOMIAS RENTISTAS: O CASO DA VENEZUELA Resumo}

As economias rentistas, ou seja, aquelas que dependem da renda gerada por uma atividade econômica, geralmente da exportação de algum produto básico como o petróleo, não podem experimentar um processo de desenvolvimento sustentável, já que ao depender de atividades econômicas mutáveis e voláteis, que estáo sujeitas a realidades externas, fora de seu controle, se transformam em economias vulneráveis. Tradicionalmente, aplicam políticas econômicas pró-cíclicas, que geram bonança nos períodos de altos preços do produto que exportam, mas em recessão, empobrecimento e inflação nos períodos de baixos preços. Nelas se valoriza notavelmente a moeda nos anos de bonança, para logo sofrer massivas desvalorizaçóes com efeitos devastadores.

Palavras-chave: Economia rentista, Doença holandesa, Vulnerabilidade econômica, Fundos de estabilização, Diversificaçấo econômica.

\section{食利型经济的风险和后果——委内瑞拉案例}

佩德罗・A・帕尔马

概要

食利型经济, 也就是那些依赖某种经济活动产出的利润, 通常是输出诸如 石油之类基本产品的经济类型。它无法经历一个可持续发展的过程，因为 一旦依赖那些不断变化和损耗的经济活动，而这些活动又受不可控制的外 部因素的支配, 它就会变得脆弱而不稳固。传统上, 在出口产品处于高价 位时采用顺周期经济政策但一旦跌落至低价位, 就出现经济衰退、贫困加 剧及通货膨胀。在经济景气时期, 货币明显地升值, 可随后便会遭受大幅 贬值, 带来毁灭性的后果。

关键词：食利型经济, 荷兰病, 经济脆弱, 稳定资金, 经济多样化 
Durante las últimas décadas la economía venezolana ha sido identificada como "rentista", un término que resume su condición de dependencia de la renta generada por la actividad petrolera. El Estado, como único dueño de las riquezas del subsuelo, ha percibido ingentes recursos de la explotación de los hidrocarburos a través del cobro de impuestos y otros gravámenes, particularmente en los años en los que se han producido abruptos aumentos de los precios de exportación, lo que ha permitido la implementación de políticas de gasto ampliamente expansivas, con importantes repercusiones en la economía interna. Esto ha llevado a la conformación de una estructura económica conocida como capitalismo rentístico (ver Baptista, 1989 y 2005 y Palma, 1989).

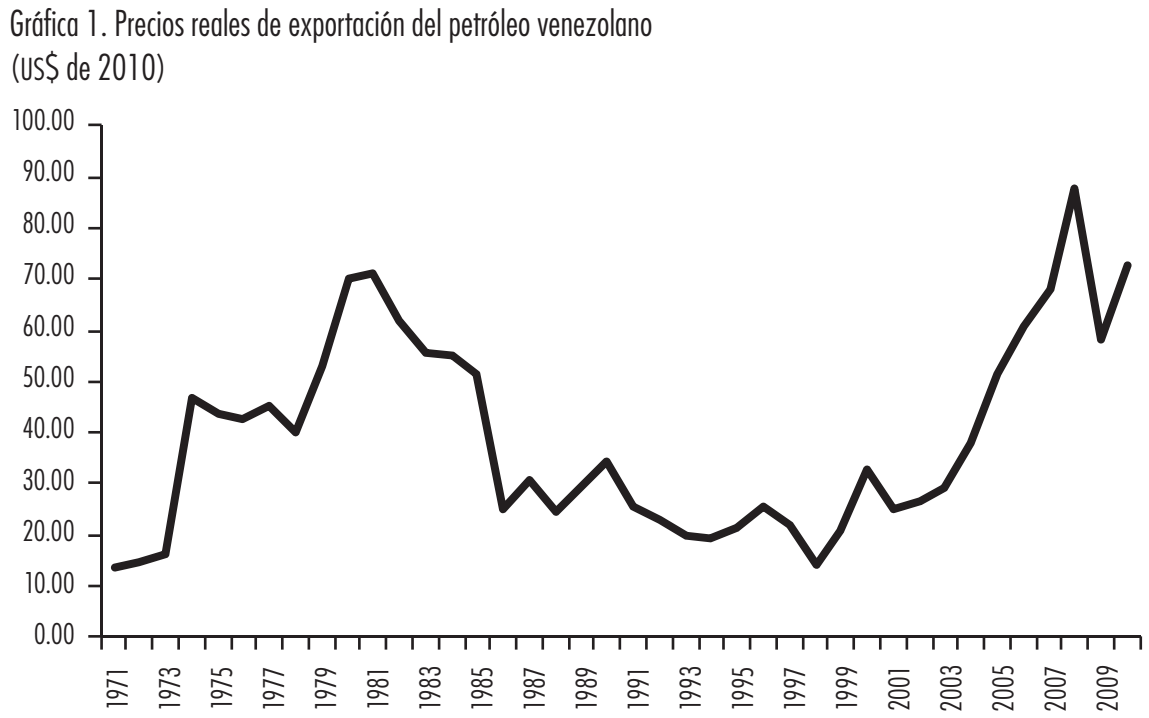

Fuente: Ministerio de Energía y Minas, US Department of Labor y cálculos propios.

Como puede verse en la gráfica anterior, desde 1974 se han producido severos cambios en el comportamiento de los precios reales de exportación, pudiendo distinguirse periodos de grandes aumentos como los de 1974, 1979-1981 y 2004-2008; de aumentos más moderados y aislados como los de 1990 (Guerra del Desierto) y 1999-2000 (recuperación de las economías asiáticas); así como periodos de reducción y de estabilidad de los mismos. Esas variaciones han coincidido con el comportamiento de la renta petrolera de origen externo, notándose una alta correlación entre ambas variables. 
Pedro A. Palma

Gráfica 2. Renta petrolera real

(US\$ de 2010)

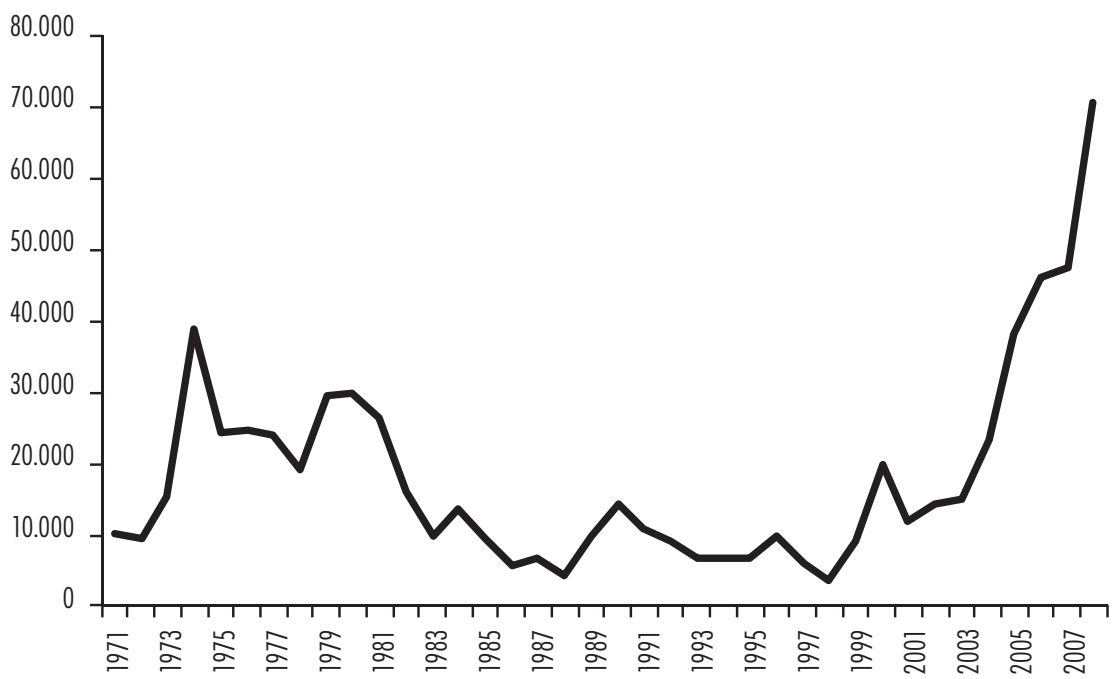

Fuente: Baptista, 2011.

En un reciente estudio sobre la incidencia de la política fiscal en la economía venezolana (Zambrano, 2010: 86-90), se demuestra que en los periodos de mayores ingresos producidos por altos precios petroleros el gobierno se inclina por implantar políticas de franca expansión de gasto público, mecanismo a través del cual se inyectan a la economía los recursos externos adicionales del petróleo. En efecto, Zambrano demuestra que en los periodos 1974-1977, 1980-1981, 19901991 y año 2000 el sesgo de la política fiscal fue típicamente expansivo, pudiendo catalogarse la misma como procíclica, ya que los gastos y los ingresos fiscales se comportaron como factores que lejos de buscar la estabilización macroeconómica, reforzaron las fases del ciclo, típicamente expansivas en esos años. ${ }^{1}$ También puede decirse que una situación similar se presentó en el periodo 2004-2008, cuando se implementó una política de gasto francamente expansiva en respuesta a las altas y crecientes rentas externas de esos años.

Previo a los cambios abruptos de mediados de los años 70 y subsiguientes, los precios fueron bastante estables, generándose una renta sostenida y relativamente abundante en el tiempo. En un país más pequeño, con una población

1 Una excepción a esta regla se dio en el periodo 1980-1981, cuando se produjeron contracciones del producto a pesar de la política fiscal con sesgo expansivo que se implantó. La explicación a este fenómeno se explica más abajo. 
mucho menor y con necesidades más básicas y poco diversificadas, como era la Venezuela de mediados del siglo pasado, esa renta petrolera permitió la implementación de una política de inversiones en infraestructura e industrias básicas, además del estímulo y el financiamiento para el desarrollo industrial privado, importaciones de maquinarias y equipos, y la materialización de importantes desarrollos habitacionales, educativos y sanitarios.

Como resultado, ese país disfrutó de un elevado y sostenido crecimiento económico durante varias décadas, con una de las inflaciones más bajas del mundo y una de las monedas más sólidamente estables. ${ }^{2}$ Eso generó un importante dinamismo social que se tradujo en la consolidación de una clase media pujante, y en la reducción sostenida de la pobreza. Ésos fueron, sin duda, los años dorados de Venezuela.

El abrupto incremento de los precios petroleros a mediados de la década de los setenta parecía indicar la profundización de aquella bonanza de los años anteriores. La entrante administración del presidente Pérez en 1974 puso en marcha una política de franca expansión de gasto con el fin de desarrollar las industrias básicas y modernizar los servicios públicos, al punto de que no bastaron los altos ingresos del petróleo, sino que se utilizó intensamente el crédito bancario internacional para financiar el creciente gasto gubernamental. Eso hizo que se pasara de una situación de amplio superávit fiscal en 1974 y 1975 a un equilibrio en 1976, para luego adentrarse en déficits fiscales cada vez más acentuados en los dos años subsiguientes (ver Gráfica 3, superior). La cuantiosa inyección de recursos estimuló el consumo y la inversión del sector privado en ese lapso, haciendo que la demanda interna total mostrara un gran dinamismo, y que la actividad productiva creciera a tasas muy elevadas (ver Gráfica 4).

Sin embargo, la oferta interna no podía expandirse al ritmo que lo hacía la demanda, entre otras razones porque existían limitaciones estructurales, como escasez de mano de obra especializada e infraestructura física poco desarrollada, siendo necesario incrementar notablemente las importaciones para compensar aquel desbalance. Eso impidió que la inevitable escalada inflacionaria que tenía que producirse se desbocara, por lo menos en el sector de los transables, pero también contribuyó a crear un déficit creciente en la cuenta corriente de la balanza de pagos, ya que después del aumento de las exportaciones nominales de 1974 éstas se estabilizaron, e incluso se contrajeron en 1978, cuando los precios

2 Durante varias décadas, Venezuela tuvo un régimen de tipo de cambio fijo, aunque en algunos casos con tasas diferenciales. Sin embargo, ello no se tradujo en situaciones de apreciación real de la moneda, ya que la inflación interna que se materializó durante muchos ańos fue similar, o incluso inferior, a la que padecían sus principales socios comerciales (ver Palma, 2008: 461-532). 
petroleros bajaron en respuesta a una situación de sobreoferta (ver Gráfica 3, inferior). Esto, combinado con la incertidumbre acerca de la estabilidad del bolívar, estimuló la salida de capitales, agravándose así el desequilibrio externo.

Como puede verse en la Gráfica 3, al final del quinquenio del presidente Pérez (1978) la economía se encontraba en una situación precaria, caracterizada por severos desequilibrios en las transacciones externas y en las finanzas públicas. Eso llevó al convencimiento de que la administración entrante implementaría un severo ajuste, siendo la devaluación del bolívar uno de sus componentes más probables, debido al déficit externo y a la alta sobrevaluación cambiaria que entonces existía. El mantenimiento de una tasa de cambio fija, combinado con una inflación interna superior a la externa, hizo que el bolívar se sobrevaluara, incentivando las importaciones y minando la competitividad del aparato productivo local frente al foráneo.

Gráfica 3.
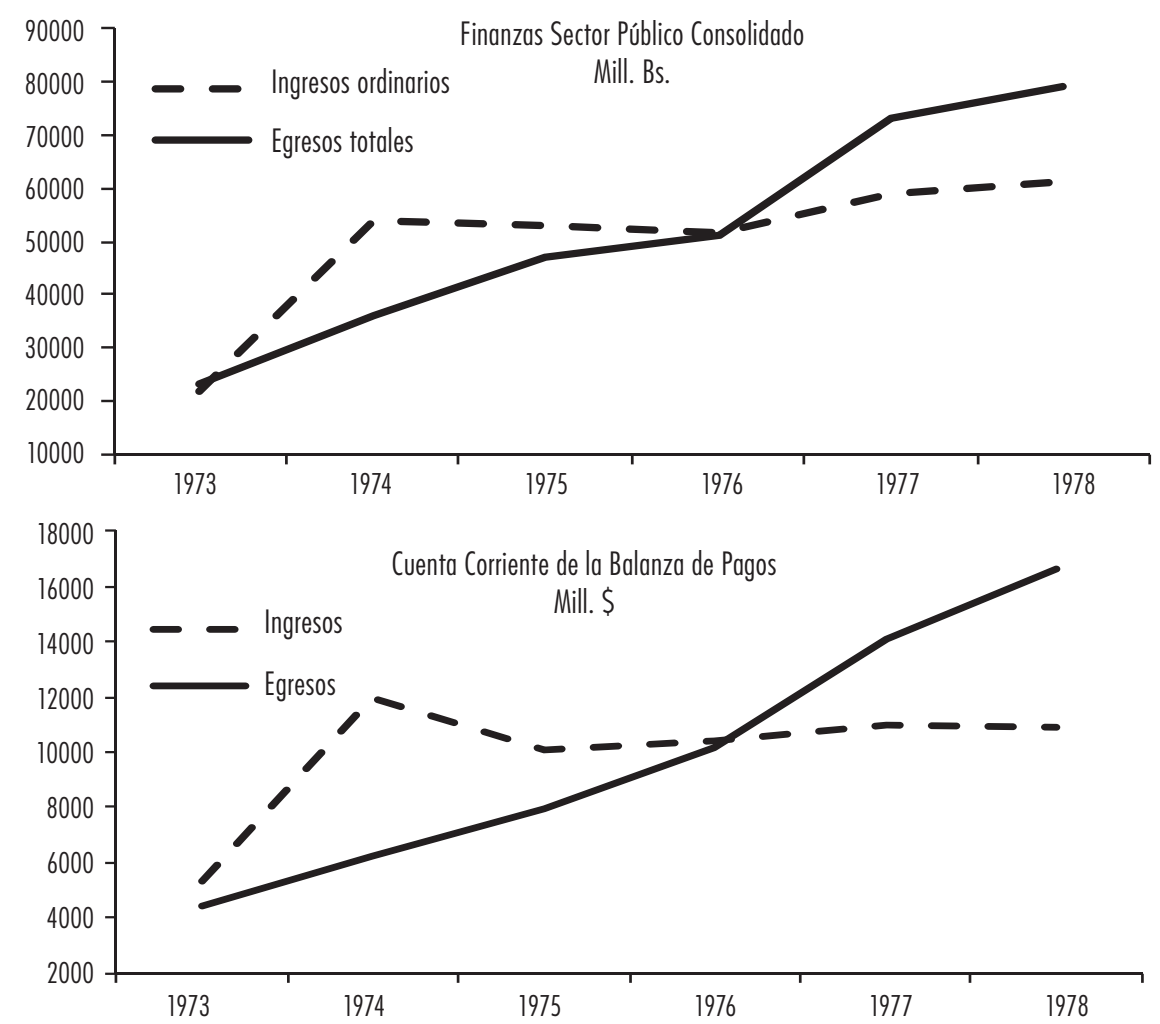

Fuente: BCV, Ministerio de Hacienda y cálculos propios. 
Esto se obvia en la Gráfica 5, donde se observa que en esos años el tipo de cambio efectivo real estuvo por debajo del nivel de paridad de equilibrio, lo que equivale a una sobrevaluación de la moneda, la cual tendió a profundizarse en el tiempo. Sin embargo, el ajuste no se produjo debido a un inesperado y radical giro del mercado petrolero internacional.

La crisis iraní de 1979, seguida por el estallido de la guerra entre Irán e Irak en septiembre de 1980, produjo la segunda crisis energética mundial, caracterizada por una nueva escalada de precios petroleros.

El mayor ingreso de divisas eliminó el déficit de la cuenta corriente a fines de 1979 y generó abultados superávits a partir de 1980. Ello contribuyó, por una parte, a eliminar las expectativas de devaluación, y por la otra, a reiniciar una política expansiva de gasto público. Sin embargo, en esta oportunidad no se produjo la bonanza de mediados de los años 70 , ya que buena parte de los recursos que se inyectaban salían al exterior, no tanto por el temor a la devaluación, sino por los altos intereses existentes en los mercados financieros internacionales, ${ }^{3}$ situación que forzó a las autoridades monetarias a elevar considerablemente las tasas de interés internas para así competir con las externas. Como producto de lo anterior, el consumo privado perdió el dinamismo de los años previos y la inversión privada se contrajo intensamente, no sólo debido los elevadísimos rendimientos que podían obtenerse en los mercados financieros internacionales, sino también por el alto costo del financiamiento y la amplia disponibilidad de capital ocioso debido a las cuantiosas inversiones que se realizaron en los años previos (ver Gráfica 4). Esto hizo que la tasa de variación interanual promedio del PIB real en el periodo 1979-1981 fuera -0.3\%.

Otro factor que contribuyó a limitar la actividad económica en ese periodo fue la aparición de mayores presiones inflacionarias, en parte debido a la materialización de una inflación represada y a problemas de altos costes de producción. Así, en 1979 y en 1980 se padecieron aumentos de precios anuales de 20\%, desconocidos históricamente.

La situación empeoró en 1982, cuando un nuevo debilitamiento de los precios petroleros, combinado con la crisis de México, deterioró las expectativas,

3 La política monetaria severamente restrictiva que se implantó en los EEUU a partir de 1979 por el nuevo presidente de la Reserva Federal, Paul Volker, elevó las tasas de interés en forma abrupta y muy intensa, generándose una transferencia masiva de fondos de todas partes del mundo hacia los Eevu o hacia el mercado de eurodólares. Esto obligó a las economías, tanto las desarrolladas como las emergentes, a elevar sus tasas de interés internas para competir con las que imperaban en las áreas del dólar. 
arreciando las salidas masivas de capital. De hecho, la creciente sobrevaluación de la moneda debido al mantenimiento del tipo de cambio fijo vigente desde hacía muchos años, y a la materialización de una inflación interna muy superior a la de los principales socios comerciales de Venezuela, así como la desaparición del financiamiento bancario internacional, llevaron al convencimiento de que, al igual que lo sucedido con el peso mexicano en febrero de 1982, el bolívar sería inevitablemente devaluado, estimulándose la fuga de capitales. Ello hizo que en febrero de 1983 se estableciera un control de cambios con tipos de cambio diferenciales, terminando así el sistema de libre convertibilidad con tipo de cambio fijo que imperó por mucho tiempo. Esas decisiones cambiarias implicaron una devaluación del bolívar que corrigió en parte la sobrevaluación (ver Gráfica 5).

En 1983, último año del gobierno del presidente Herrera Campíns, se materializó una crisis caracterizada por: 1) un importante desequilibrio externo; 2) un alto endeudamiento con la banca internacional cuyo refinanciamiento se difirió por la negativa del gobierno de implantar una política de ajuste en un año electoral; 3) una renta petrolera en franca contracción que contribuyó a generar una estrechez fiscal, que se agravaba por la imposibilidad de obtener financiamiento externo; 4) una profunda recesión; y 5) un deterioro de la calidad de vida de los venezolanos. Ello llevó a la administración del presidente Lusinchi a implantar políticas económicas de ajuste tendentes a afrontar los desequilibrios heredados, haciendo que en 1984 y 1985 se implantara una política fiscal

Gráfica 4. Variaciones \% de variables de demanda real

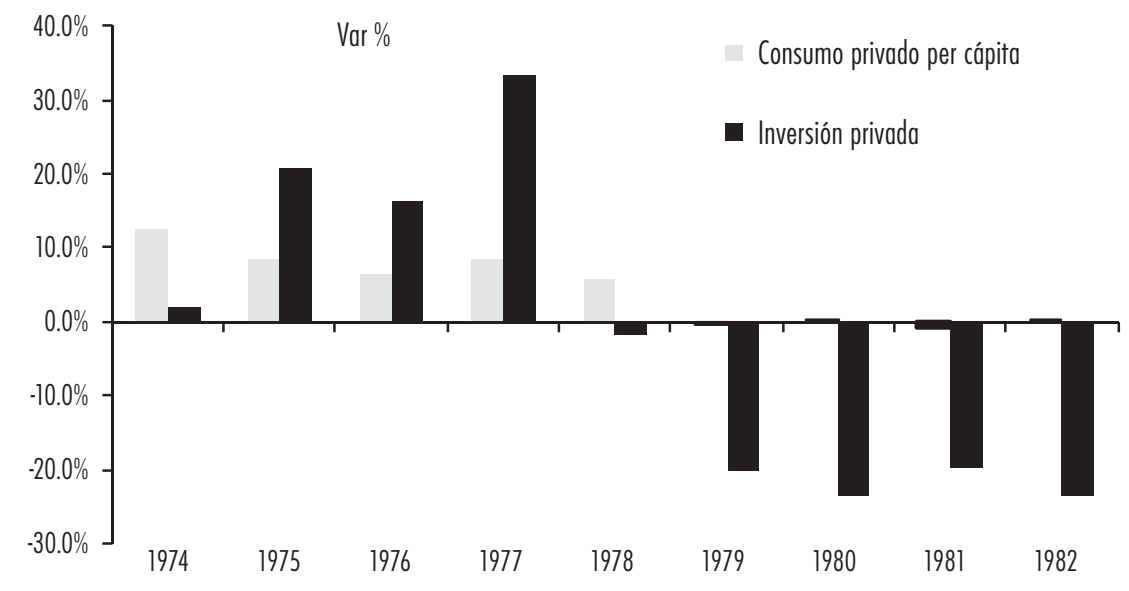

Fuente: BCV y cálculos propios. 
Gráfica 5. Índice de tipo de cambio efectivo real

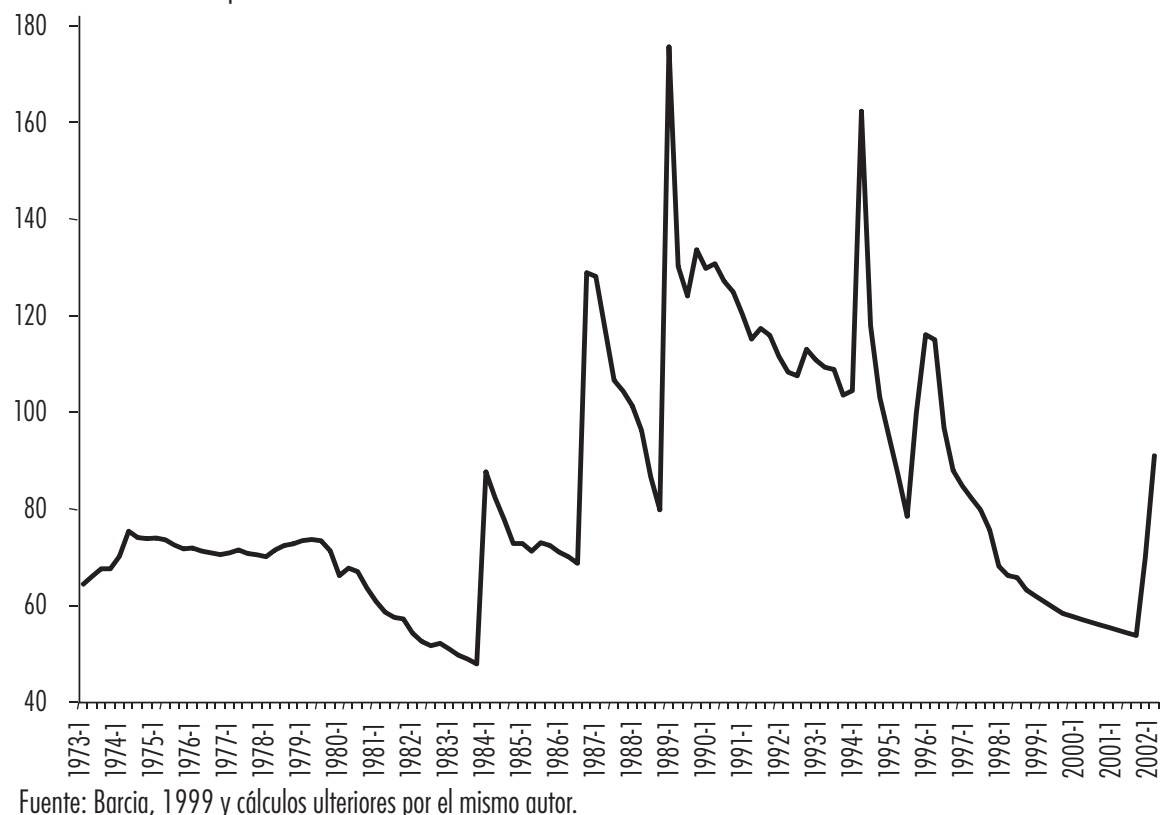

contractiva que contribuyó a que en esos años la economía continuara estancada y el desempleo llegara a superar el 13\%.

A fines de 1985 el gobierno decidió poner fin al ajuste e implantar una política fiscal expansiva con el fin de estimular la actividad económica, para lo cual contaba con recursos ahorrados durante el periodo de ajuste. Sin embargo, en febrero de 1986 se desplomaron los precios petroleros, manteniéndose éstos en niveles mucho menores que en los años precedentes durante el resto de la administración de Lusinchi (1986-1988). No obstante, la política expansiva de gasto continuó, generándose déficits de importancia. Ello contribuyó a que se devaluara el bolívar en diciembre de 1986, medida que generaría ingresos fiscales adicionales en moneda local. Si bien esa devaluación corrigió la sobrevaluación de la moneda que entonces existía, la misma rápidamente volvió a aparecer, ya que el nuevo tipo de cambio oficial se mantuvo inalterado por dos años, a pesar de que la inflación interna era mucho mayor que la externa.

A finales de 1988, después de seis años de control cambiario, la economía sufría grandes problemas. Además del desequilibrio fiscal, la congelación de las tasas de interés a niveles artificialmente bajos y divorciados de la realidad inflacionaria, se tradujo en una sobredemanda de créditos y en dificultades crecientes 
para la banca de captar depósitos del público, generando ello un desequilibrio en el mercado financiero y monetario. Adicionalmente, la estabilización de las exportaciones petroleras, combinada con las crecientes importaciones debido al mayor nivel de actividad económica y a la sobrevaluación de la moneda, generó déficits crecientes de la cuenta corriente y una pérdida sostenida e intensa de reservas internacionales. Todo lo anterior creó una situación insostenible que exigía la aplicación de un plan de ajuste orientado a corregir los profundos desequilibrios existentes.

Eso hizo que a comienzos de 1989 la administración entrante, encabezada por Carlos Andrés Pérez, implantara un plan de ajuste, eliminando el control de cambios y unificando la tasa cambiaria a los niveles prevalecientes en el mercado paralelo, implicando una devaluación del bolívar muy intensa. Adicionalmente, se comenzaron a sincerar las tarifas de los servicios públicos y los precios de varios productos básicos como la gasolina, y se firmó una carta de intención con el Fondo Monetario Internacional con su consiguiente condicionamiento. La implementación de ese plan de ajuste fue traumática, ya que a los pocos días de haber comenzado el nuevo periodo presidencial se produjo el estallido popular conocido como "El Caracazo", en buena medida como respuesta a las sorpresivas medidas de ajuste que muy poca gente esperaba, menos viniendo de un hombre como el presidente Pérez, recordado como el promotor de la gran bonanza petrolera de mediados de los años setenta durante su primer mandato. Como consecuencia de los severos correctivos, ese año el PIB se contrajo 8.6\%, la inflación se ubicó en 82\%, y la caída del poder de compra del ingreso del venezolano fue muy intensa.

No obstante, la recuperación de los precios y de la renta petrolera en 1990 como consecuencia de la Guerra del Desierto posibilitó la aplicación de una política fiscal expansiva que se tradujo en una importante recuperación de la economía. A su vez, los esfuerzos por crear un clima propicio a la inversión, el desmantelamiento de los férreos controles del pasado, y la implementación de una política cambiaria realista que buscaba evitar la sobrevaluación de la moneda a través de minidevaluaciones periódicas, ${ }^{4}$ parecía prometer un cambio de rumbo en la conducción de la economía. Sin embargo, en 1992 todo cambió con el descalabro político causado por dos intentos de golpe de Estado, seguidos por un hostigamiento político contra el presidente Pérez liderado por su propio partido, Acción Democrática, debido a la pérdida de prebendas de otrora, que

4 En el segundo gobierno de Pérez se implantó una política cambiaria de minidevaluaciones periódicas, o crawling peg, que evitó la reaparición de la sobrevaluación de la moneda, aun cuando se operó una sostenida apreciación real del bolívar, pero de moderada intensidad (ver Gráfica 5). 
llevó a su destitución en 1993 y al establecimiento de un gobierno de transición encabezado por Ramón J. Velásquez.

El 13 de enero de 1994, tan sólo un par de semanas antes de la toma de posesión del presidente Rafael Caldera, ganador de las elecciones de diciembre de 1993, fue intervenido el Banco Latino, el segundo más grande del sistema, dándose así inicio a la crisis financiera más profunda y costosa que haya sufrido Venezuela. La ausencia de una normativa bancaria moderna, la débil supervisión estatal, la baja capitalización de varias instituciones financieras, el elevado porcentaje de cartera relacionada y las cuantiosas inversiones ilíquidas y de alto riesgo de varios bancos, fueron algunos de los factores principales que gestaron la crisis bancaria sistémica, cuya dimensión y gravedad se pueden catalogar de dramáticas, en buena medida debido a su mal manejo por parte de la administración entrante. ${ }^{5}$ La misma afectó a un elevado número de instituciones financieras donde estaba más del $54 \%$ de los depósitos, generándose una fuga masiva de capitales que llevó a la imposición de un nuevo control de cambios a partir de comienzos de julio de 1994. Ese control se caracterizó por el establecimiento de un único tipo de cambio fijo oficial que estuvo vigente durante 18 meses, a pesar de padecerse una inflación local muy superior a la externa.

Las consecuencias no se hicieron esperar. La actividad económica mostró una contracción de importancia, entre otras razones por la caída del consumo y de la inversión, así como por la restricción en la asignación de divisas, que produjo problemas de desabastecimiento. La inflación, por su parte, también repuntó considerablemente, en particular en 1995, ya que la baja disponibilidad de dólares preferenciales hizo que la tasa de cambio libre se disparara y se divorciara de la oficial, generándose incrementos muy abruptos de los costos esperados de reposición, y con ellos el aumento sostenido y cada vez más acentuado de los precios. La situación hizo crisis a comienzos de 1996, cuando la inflación anualizada se ubicó en 150\%, nivel insostenible y explosivo en una economía sin indexación de salarios y ajustes automáticos en línea con la inflación.

En marzo de ese año se procedió a desmantelar el control cambiario y a unificar el tipo de cambio en niveles similares a los existentes en el mercado libre, produciéndose una maxidevaluación ${ }^{6}$ con efectos devastadores sobre la población, de forma muy similar a lo acontecido en 1989, contrayéndose la capacidad

5 Para un análisis pormenorizado de la crisis financiera de 1994, sus orígenes y consecuencias, ver (Krivoy, 2002), (García, Rodríguez y Salvato, 1997), (Faraco, 2008: 10-82) y (Palma, 1999: 99-104).

6 El tipo de cambio controlado pasó de Bs/\$ 170 a comienzos de diciembre de 1995, nivel en el que se encontraba desde julio de 1994, a Bs/\$ 470 en abril de 1996 (ver Gráfica 5). 
de compra del ingreso y reduciéndose el consumo. La caída de la demanda hizo que el PIB no-petrolero también mostrara una importante contracción, a pesar de la recuperación de la inversión ocurrida en los últimos meses de 1996 en respuesta a la apertura petrolera y al clima más favorable a la actividad privada.

La implantación de un sistema de bandas cambiarias a partir de julio de ese año sustituyó al control de cambios. De acuerdo con el nuevo sistema, la tasa de cambio nominal fluctuaría en torno a una paridad central que aumentaría mensualmente en línea con el diferencial inflacionario interno y externo, pero siempre manteniéndose dentro de una franja definida por un límite superior y otro inferior. Lo que realmente sucedió, desde el inicio del nuevo esquema, fue un anclaje del tipo de cambio nominal, buscándose con ello la reducción de la inflación. Esto obligó a que cada seis meses se tuviera que quebrar la banda hacia abajo para evitar que el tipo de cambio nominal se saliera de su límite inferior. La cuasi fijación de la tasa cambiaria nominal, combinada con una inflación interna aún muy superior a la externa, volvió a generar el fenómeno recurrente de la sobrevaluación cambiaria creciente, tan característico del capitalismo rentístico, ${ }^{7}$ que se mantuvo hasta comienzos de 2002, cuando se eliminó el sistema de bandas y se implantó la libre flotación de la tasa de cambio, devaluándose el bolívar y corrigiéndose la sobrevaluación (ver Gráfica 5).

La recuperación de los precios del petróleo durante los últimos meses de 1996 y buena parte del año siguiente, así como el clima de confianza creado por la política económica más realista y sin tantos controles que se implementaba, llamada la Agenda Venezuela, ayudó a que en 1997 se volviera a producir una recuperación de la actividad productiva. No obstante, la contracción de los precios internacionales de los hidrocarburos que siguió al estallido de la crisis asiática a mediados de ese año volvió a afectar a Venezuela, máxime cuando se retrasó parte de las reformas estructurales de la Agenda Venezuela, y la sobrevaluación del bolívar se intensificó de forma persistente. Adicionalmente, el clima político se enrareció a medida que avanzaba el año 1998, ya que Chávez se perfilaba como el candidato ganador en las elecciones de diciembre, introduciendo esto un factor de incertidumbre adicional. Todo ello se conjugó para estimular salidas masivas de capitales que forzaron al Banco Central de Venezuela (вСv) a implantar una política monetaria muy restrictiva para limitar la cantidad de bolívares que se pudieran canalizar a la adquisición de divisas. Esto generó un aumento abrupto de las tasas de interés, habiendo momentos en que éstas llegaron a niveles superiores al 30\% en términos reales, evitándose así que se produjera la esperada

7 Ver Palma, 1999: 129-131. 
devaluación. Esas circunstancias vividas en 1998 generaron contracción económica, alta inflación, sobrevaluación creciente de la moneda, menores posibilidades de empleo y desmejora en la calidad de vida de la población.

Recapitulando, el balance del manejo errático y volátil de la economía durante las últimas décadas del siglo $\mathrm{xx}$, caracterizado por un fuerte sesgo rentístico fue muy negativo. Desde fines de los años setenta la población padeció un proceso sostenido de empobrecimiento caracterizado por una caída del PIв per cápita y del salario real promedio, revirtiéndose así aquel dinamismo social y mejora en la calidad de vida que se vivió en las décadas de 1950, de 1960 y parte de los setenta (ver Gráfica 6).

Un factor que contribuyó al agravamiento de ese proceso adverso fue la reiterada práctica de varios gobiernos de postergar los ajustes requeridos para afrontar las reducciones de los ingresos petroleros con el fin de evitar el costo político, pasando irresponsablemente el problema a la siguiente administración. Esto agravaba los desequilibrios y aumentaba los efectos nocivos de los ajustes que inevitablemente tenían que ser hechos por los gobiernos siguientes.

Esto explica, en buena medida, por qué los venezolanos buscaron un cambio de rumbo en la conducción del país, y por qué en las elecciones presidenciales de diciembre de 1998 más del 90\% de los electores dieron sus votos a dos candidatos que no eran miembros del liderazgo político tradicional, ganando Hugo Chávez.

Gráfica 6. Cinco décadas contrastantes

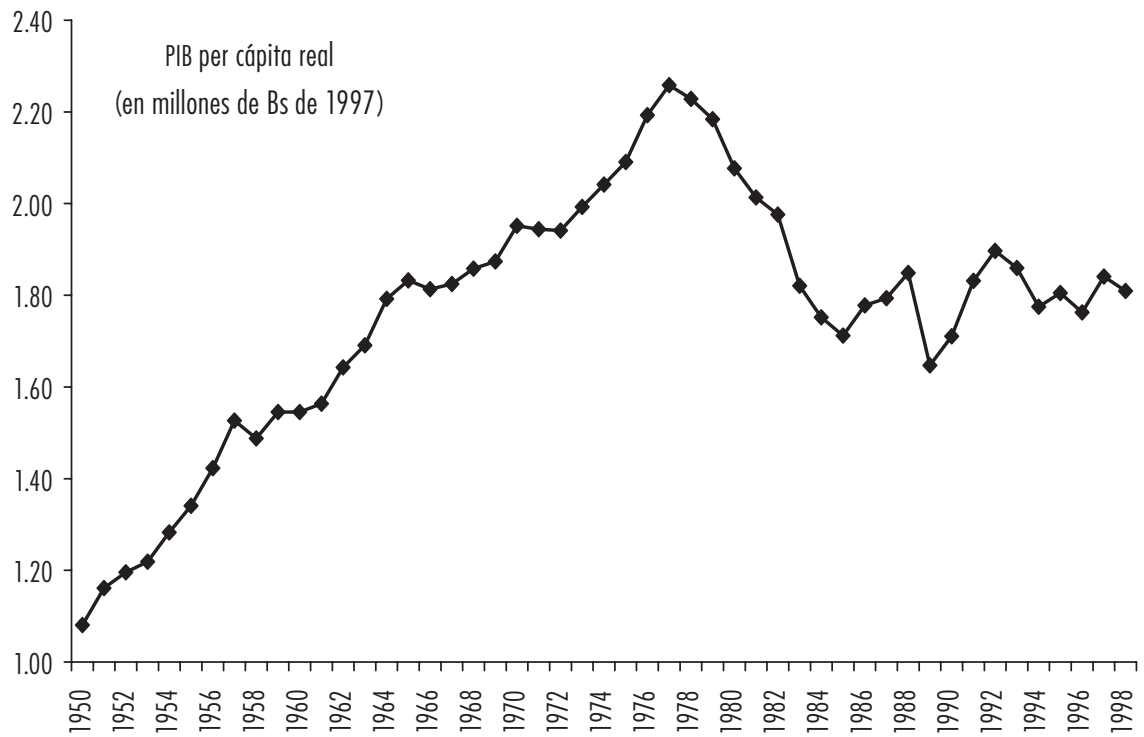

Fuente: Banco Central de Venezuela (BCV) e Instituto Nacional de Estadísticas (INE). 


\section{LA POLÍTICA ECONÓMICA DE CHÁVEZ}

Las expectativas económicas y políticas después de las elecciones y durante los inicios de la nueva administración no podían ser más sombrías. Los precios petroleros colapsados, combinados con la incertidumbre acerca de la orientación e intención del nuevo gobierno, crearon aquel clima tan adverso. Sin embargo, el presidente electo actuó decididamente transmitiendo mensajes tranquilizadores que inspiraron confianza, entre ellos la promesa de implementación de políticas sociales orientadas a mejorar la condición de vida de los más pobres.

El problema urgente era atender los bajos precios de los hidrocarburos. A comienzos de 1999 éstos se encontraban en uno de los niveles más bajos en varias décadas, estimándose para ese año un nivel promedio de us\$ 9,00 por barril. Sin embargo, el fortalecimiento de la demanda mundial debido a la recuperación de las economías asiáticas y los recortes de producción de la OPEP, modificaron aquel sombrío panorama desde el segundo trimestre, haciendo que el precio promedio para ese año terminara en us $\$ 16,04$ por barril, y que en 2000 alcanzara los us $\$ 25,91$.

Otra prioridad del gobierno entrante fue la reducción de la inflación, la cual había llegado a 30\% en 1998. A tales fines se decidió continuar la política cambiaria implantada por Caldera desde julio de 1996, manteniéndose el anclaje del tipo de cambio nominal dentro del sistema de bandas con el fin de abaratar los productos foráneos; la inflación cayó a 20\% en 1999.

Se eligió una Asamblea Constituyente a mediados de 1999 con una amplísima representación gubernamental, que estructuró en muy breve plazo un nuevo proyecto de Carta Magna; éste fue sometido a referéndum el 15 de diciembre de ese año, siendo aprobado. Aunque el documento contenía algunos artículos controversiales, contribuyó a disipar muchas dudas, pues las cláusulas económicas reflejaban pocas diferencias con las incluidas en la Constitución anterior, minimizando así los temores de implantación inminente de un sistema socialista en el país.

El ambiente de incertidumbre y los bajos precios petroleros contribuyeron a crear un clima económico muy negativo que se tradujo en una severa caída de la actividad productiva, haciendo que el PIB se contrajera un $6.1 \%$ en 1999. Sin embargo, al igual que en el pasado, la mejora de las exportaciones debido a la recuperación de los precios petroleros llevó a la nueva administración a aplicar una política de expansión del gasto público, aunque también decidió ahorrar parte del ingreso petrolero adicional producido por los mayores precios en un Fondo de Estabilización Macroeconómica (FIEM), donde se atesoraron más de us\$7.000 millones en los tres primeros años de gobierno. 
No obstante, en forma simultánea la deuda pública interna aumentó en us\$ 10.800 millones. Es decir, por un lado el sector público ahorraba, pero por el otro se endeudaba. Como producto de la política fiscal expansiva y de la sobrevaluación creciente de la moneda debido al anclaje del tipo de cambio, en el año 2000 la actividad económica creció un 3.6\% en términos reales y la inflación bajó a 13.4\%, resultados nada espectaculares, pero mejores que los del año precedente.

\section{1, un ańo problemático}

El inicio de una situación recesiva en los Estados Unidos, combinado con las secuelas del ataque terrorista del 11 de septiembre de 2001, hizo que los precios internacionales del petróleo volvieran a caer ese ańo, revirtiéndose así la tendencia alcista que se había materializado desde el segundo trimestre de 1999. A pesar de ello, el gobierno insistió en mantener la política fiscal expansiva que venía implementando, para lo cual incrementó su endeudamiento interno y dejó de hacer nuevos aportes al FIEM, lográndose un crecimiento del pIB de 3.4\%. Por su parte, la continuación de la política de anclaje del tipo de cambio hizo que siguiera aumentando la sobrevaluación del bolívar, contribuyendo de esta manera a que la inflación fuera de $12.3 \%$, similar a la del año precedente.

Sin embargo, la economía estaba en el preámbulo de una crisis de grandes dimensiones. El debilitamiento de los precios petroleros, combinado con el deterioro de las expectativas debido a una situación política cada vez más tensa, se tradujo en salidas masivas de capitales, caída de reservas internacionales y desestímulo creciente a la inversión. La confrontación creciente del presidente Chávez con el sector empresarial y con los opositores al régimen experimentó una escalada de importancia al dictarse una serie de decretos-ley muy polémicos y controversiales que afectaban aspectos álgidos de la vida nacional, tales como la política petrolera, la propiedad de la tierra, y otras. En respuesta, la oposición redobló las protestas y convocó a un paro cívico para el 10 de diciembre que paralizó al país por un día.

\section{2, un año crítico}

El 12 de febrero de 2002 se anunció la finalización del esquema de bandas cambiarias con anclaje del tipo de cambio, siendo éste sustituido por una libre flotación de la tasa cambiaria, lo que implicó una devaluación importante del 
bolívar. ${ }^{8}$ No obstante, las salidas de capitales continuaron, con la consecuente presión sobre el tipo de cambio flotante. Esto se debió a: 1) el enfrentamiento del gobierno con la planta gerencial y técnica de Pdvsa que se oponía a la nueva política petrolera y a la politización de la industria; 2) las tensiones políticas cada vez mayores que desembocaron en el derrocamiento efímero del presidente Chávez por los graves sucesos del 11 de abril, y su retorno al poder dos días más tarde; y 3) el clima de incertidumbre existente. Esto forzó al BCV a implantar una política monetaria restrictiva que elevó sustancialmente las tasas de interés, generándose un incremento importante de la morosidad de la cartera de la banca. Esto último, unido a la pérdida de depósitos que se fugaban al exterior y al aumento de las obligaciones en moneda extranjera debido a la devaluación, creó una situación difícil para las instituciones financieras locales, compensada en parte por las utilidades cambiarias que obtuvieron al revalorizarse sus activos en moneda extranjera debido a la modificación del tipo de cambio.

El encarecimiento de las importaciones, la implantación de un impuesto al débito bancario, el ajuste compulsivo del salario mínimo, y los mayores costos financieros debido al aumento de la tasa de interés, se aunaron para generar un repunte inflacionario de importancia, haciendo que el índice de precios al consumidor aumentara $31.2 \%$, y que el poder de compra de la población se contrajera.

El gobierno insistió en su política fiscal expansiva, incrementándose sus necesidades de financiamiento. Esto hizo que se utilizaran los recursos previamente ahorrados en el FIEM, se siguiera acrecentando su endeudamiento interno, y se buscaran fuentes alternativas de financiamiento, tales como las utilidades cambiarias del BCV.

No obstante, el PIв de ese ańo se contrajo en 8.9\%, contribuyendo para ello la reducción de la producción petrolera en respuesta a la decisión de la OPEP de bajar las cuotas de sus miembros para así limitar la oferta mundial y fortalecer los precios. Otros factores también incidieron en la contracción del producto, pudiéndose mencionar entre éstos: los efectos recesivos de la devaluación; la contracción del consumo privado por la pérdida de la capacidad de compra de la población; las restricciones crediticias y las mayores tasas de interés; la severa caída de las inversiones, y las elevadas salidas de capital. La adversidad se acentuó de manera dramática a fines de ese año con el paro cívico nacional iniciado en diciembre y que se extendió hasta febrero del año siguiente, el cual generó, entre otras cosas, la paralización de la producción petrolera.

8 El tipo de cambio pasó de Bs/\$ 773 el 8 de febrero de 2002, último día de vigencia del esquema de bandas, a Bs/\$1.496 ocho meses más tarde. 


\section{3, un año caótico}

El PIB del primer trimestre de 2003 se contrajo 25.1\% en comparación con igual lapso del ańo anterior, y los despidos masivos debido a la quiebra o a la reducción forzada de operaciones de múltiples empresas, llevó el desempleo a niveles de $18 \%$. Ello, combinado con un subempleo superior al $50 \%$ y con una caída del poder de compra de las personas, se tradujo en una situación laboral crítica y en el agravamiento del problema de la pobreza. Adicionalmente, el despido de más de 18.000 empleados de Pdvsa, básicamente gerentes altos y medios, empleados y técnicos especializados, tuvo consecuencias dramáticas en la principal industria del país que aún persisten.

Las condiciones caóticas que se vivían a comienzos de ese año incentivaron aún más la fuga de capitales, generando un abrupto encarecimiento del dólar y una fuerte caída de las reservas internacionales. El 22 de enero, el BCv suspendió todas las operaciones en divisas, y dos semanas más tarde se impusieron severos controles de cambio. También se aplicó un estricto y arbitrario control de precios que condenó a muchos productores a trabajar con estrechos márgenes o incluso a pérdida, viéndose muchos de ellos obligados a suspender operaciones. Durante los primeros cuatro meses del control de cambios el sistema estuvo totalmente inoperante, autorizándose la entrega de divisas para importación en cantidades mínimas y divorciadas de las necesidades de la economía.

A pesar de que en el tercer trimestre se hicieron algunos avances en la aprobación de los dólares oficiales para la importación y el servicio de la deuda, eso poco ayudó a revertir la crítica situación que se vivía. La actividad económica seguía deprimida al punto de que, después de la devastadora contracción del primer trimestre, en los seis meses siguientes continuaron observándose importantes caídas de la producción, haciendo que el PIB de ese año se contrajera en 7.8\%.

Esa situación, combinada con las severas recesiones de 1999 y de 2002, hizo que al culminar los 5 primeros años del gobierno de Chávez, el PIB per cápita real fuera un $24 \%$ menor que el de 1997 y $16.2 \%$ más bajo que el de 1998 , año este último que, como arriba se indicó, fue de profunda crisis.

Los aumentos de costos generados por la devaluación hicieron que la inflación a nivel de productor y de mayorista fuese sustancialmente mayor. Sin embargo, la restricción del consumo debido al menor poder de compra de la población evitó que esos mayores costos se transfirieran en su totalidad al consumidor. ${ }^{9}$

9 La inflación a nivel de mayoristas en 2003 reportada por el BCv fue de 53.1\%, la de los productores manufactureros fue de $41.7 \%$ (diciembre 2002 a diciembre 2003), mientras que la inflación a nivel de consumidor, medida por la variación del índice de precios al consumidor del Área Metropolitana de Caracas, fue de 27.1\%. 
La turbulencia política, el descontento creciente y la menor popularidad del presidente crearon una intención cada vez más generalizada de revocarle constitucionalmente el mandato a través de un referéndum. No obstante, las dilaciones y manipulaciones de la autoridad electoral, con presencia mayoritaria del oficialismo, permitieron postergar por un año la realización del referéndum, periodo en el cual se implantaron unos programas sociales llamados "misiones" que ayudaron a recuperar la popularidad del presidente entre los segmentos más pobres de la población, impidiendo así la revocación de su mandato. ${ }^{10}$ Sin restar la importancia que estos programas tienen desde el punto de vista social, y sin cuestionar cuán efectivos son en la generación de bienestar inmediato, éstos producen importantes dividendos políticos, mas no contribuyen a resolver de forma permanente el drama de la pobreza, para lo cual se requiere, entre otras cosas, la generación de una oferta dinámica y suficiente de oportunidades de trabajo permanente y bien remunerado.

La implementación de las "misiones" implicó una política de franca expansión de gasto desde el tercer trimestre de 2003, a pesar del debilitamiento de los precios petroleros y de la mermada recaudación de tributos causada por la recesión económica. Esto, obviamente, ensanchó la brecha fiscal, lo cual hizo que el gobierno, por una parte, forzara al BCV a financiar gasto público deficitario a través de la creación de unas utilidades cambiarias ficticias y, por la otra, incrementara notablemente su nivel de endeudamiento, haciendo que la banca local comprara bonos públicos en cantidades crecientes. Ese incremento de gasto corriente hizo crecer sustancialmente la oferta monetaria a fines de ese año, estimulando el consumo y la actividad productiva del último trimestre, cuando se operó un crecimiento de cierta importancia del pIB que en algo contrarrestó las severas contracciones de los tres primeros trimestres.

\section{4 y años subsiguientes: una nueva bonanza petrolera}

El incremento de la renta petrolera debido al aumento sostenido de los precios en el periodo 2004-2008 llevó a la implementación de una política fiscal

$\overline{10}$ A través de estos programas sociales se implementaron proyectos de alfabetización, atención médica en los barrios más pobres, masificación de la educación universitaria, y venta masiva de productos de consumo a precios subsidiados a través de Mercal, una amplia red de expendios al detal creada y mantenida por el gobierno. También se otorgaron "becas" a un importante número de personas, siendo éstas simples dádivas que contribuyeron a incrementar en forma importante, pero transitoria, el ingreso disponible del segmento más pobre de la población. 
expansiva y procíclica en buena parte de ese lapso. Esto hizo que la oferta monetaria real experimentara un crecimiento interanual promedio de $34.6 \%$ en el periodo 2004-2006, a pesar de los esfuerzos hechos por el BCV por reabsorber parte de la liquidez excedente a través de la venta a los bancos de certificados de depósito remunerados.

No conformándose con los ingresos adicionales del petróleo, el gobierno hizo que la Asamblea Nacional, totalmente subordinada a la voluntad del Poder Ejecutivo, aprobara en julio de 2005 una modificación a la Ley del BCV, con el fin de obligar al instituto emisor a traspasar importantes montos de reservas internacionales al Fondo de Desarrollo Nacional (Fonden), creado y manejado por el alto gobierno para financiar gasto público. ${ }^{11}$ Esto ha tenido importantes repercusiones. Por una parte, ha implicado una descapitalización del instituto emisor, ya que al desprenderse de esos activos sin recibir compensación alguna está teniendo una cuantiosa pérdida patrimonial. ${ }^{12}$ Adicionalmente, esas operaciones generan importantes crecimientos de la oferta monetaria, pues aun cuando el gobierno utilice los dólares recibidos para hacer pagos en el exterior evitándose así su doble monetización, disponer de ellos gratuitamente implica la liberación de recursos que se pueden destinar a financiar gasto público, en vez de ser entregados al BCV como pago de las divisas en cuestión.

La elevada y sostenida expansión de la oferta monetaria estimuló notablemente las compras de bienes y servicios, máxime cuando buena parte del gasto público iba dirigido hacia las personas de bajos recursos que tienen una alta propensión al consumo; de hecho, el consumo privado real experimentó un crecimiento interanual promedio de $16.3 \%$ en el periodo 2004-2007. La formación bruta de capital fijo, por su parte, también experimentó importantes aumentos. Esto contribuyó a generar un crecimiento interanual promedio del PIB no-petrolero real de $12.2 \%$ en ese mismo lapso.

Esa bonanza se reflejó favorablemente en el sector laboral y en la población en su conjunto. El ingreso real de los venezolanos experimentó importantes

11 Entre el segundo semestre de 2005 y enero de 2011 el BCV ha transferido us $\$ 38.882$ millones de reservas internacionales al Fonden.

12 Debido a una norma contable desarrollada por la Superintendencia de Bancos y Otras Instituciones Financieras, el BCV, en lugar de registrar como pérdida patrimonial la transferencia de sus reservas internacionales al Fonden, como debe hacerse, contabiliza como contrapartida de esa pérdida de activos el aumento de unas supuestas cuentas por cobrar, que de hecho no se están produciendo, ya que el gobierno nacional no está obligado a pagar los recursos que recibe el Fonden. Este subterfugio contable evita que en los estados financieros del BCV se reflejen las cuantiosas pérdidas de activos y de patrimonio que ha venido sufriendo por esas transferencias forzosas. 
crecimientos, y el desempleo bajó notablemente, pasando de $18 \%$ en el caótico 2003 a un $8.5 \%$ en 2007, reduciendo la pobreza aunque no en forma dramática. A pesar del alto crecimiento, en 2007, después de 4 años de bonanza, más del $52 \%$ de la fuerza laboral estaba aún afectada por una situación de desempleo o de subempleo.

Dado que el crecimiento de la demanda interna era mayor que el de la producción, fue necesario complementar la oferta local con importaciones cada vez más altas, las cuales también se vieron estimuladas por el alto crecimiento de la producción y por la elevada y creciente sobrevaluación de la moneda. ${ }^{13} \mathrm{~A}$ tal punto llegó la dependencia de suministro externo que, de acuerdo con cifras del BCV, la relación importaciones de bienes y servicios a PIB de 2007 fue de 48\%.

Esa alta dependencia de suministro externo no sólo implicaba altos riesgos para una economía tan dependiente de una actividad tan volátil como la petrolera, sino que también significaba una carga muy pesada para el aparato productivo interno, cada vez menos capaz de competir con los productos importados que se adquirían con dólares artificialmente baratos. Esto último, combinado con la imposición de severos y desproporcionados controles de precios y de producción, y con el acoso permanente y cada vez más acentuado del gobierno hacia la empresa privada, llevó a que múltiples productores se vieran obligados a suspender operaciones y a desmantelar sus plantas, transformándose en importadores de los productos que antes producían, acrecentándose así la dependencia de suministro externo.

A pesar de las altas importaciones, las abultadas exportaciones petroleras aseguraban la materialización de superávits de la cuenta corriente de la balanza de pagos. Sin embargo, éstos eran compensados por déficits crecientes de la cuenta capital, generados por las exiguas inversiones extranjeras ${ }^{14} \mathrm{y}$ por las

13 Al igual que en controles de cambio previos, el que se instauró en febrero de 2003 se caracterizó por ser uno con un tipo de cambio oficial único y fijo, siendo éste ajustado en dos ocasiones: en febrero de 2004, cuando pasó de Bs/\$1.600 a Bs/\$1.920, y el 3 de marzo de 2005, cuando la tasa preferencial oficial se fijó en $\mathrm{B} s / \$ 2.150$, nivel que se mantuvo vigente durante cuatro años y diez meses. Al existir una inflación interna muy superior a la padecida por los principales socios comerciales de Venezuela, el signo monetario experimentó durante esos ańos una sostenida e intensa apreciación real, que produjo una sobrevaluación creciente del bolívar destinado a la compra de dólares preferenciales. Para un análisis detallado ver Palma, 2008: 515-529.

14 Las expropiaciones ilegales y arbitrarias, el anuncio reiterado del presidente Chávez de que Venezuela va a un "socialismo del siglo Xxı", la ausencia de independencia de los poderes públicos, la aprobación de leyes coercitivas, las reiteradas violaciones al Estado de derecho, y la decretada inamovilidad indefinida de trabajadores, son algunas de las realidades que han desincentivado la inversión privada. 
crecientes salidas de capitales privados en respuesta al clima de incertidumbre y expectativas existente. ${ }^{15}$

La inflación, por su parte, se mantuvo elevada a lo largo de estos ańos, siendo la más alta de América Latina. No obstante, los controles de precios y los masivos subsidios gubernamentales la moderaron ligeramente durante los primeros dos años de la bonanza (19.2\% en 2004 y $14.4 \%$ en 2005), a pesar de la extraordinaria expansión de la oferta monetaria. Otros factores que también contribuyeron a mitigar el aumento de los precios durante esos ańos fueron la sobrevaluación de la moneda, las ingentes importaciones gubernamentales, y la venta masiva de productos de consumo a precios subsidiados a través de Mercal. ${ }^{16}$ No obstante, en los años subsiguientes la inflación repuntó de manera importante debido al intenso aumento de la demanda, pero también a problemas de desabastecimiento creciente en respuesta a la extrema rigidez de los controles de precios, que en muchos casos estaban divorciados de las realidades de costos. Esto llevó a las autoridades a liberar esos controles a fines de 2007, haciendo que múltiples productos de consumo se encarecieran, particularmente en los primeros meses de $2008 .^{17}$

\section{8-2010, años de crisis}

Al colapsar los precios internacionales del petróleo en la segunda mitad de 2008 como producto del estallido de la crisis financiera mundial, ${ }^{18}$ era obvio que la economía venezolana sufriría un fuerte impacto, máxime cuando el modelo de bonanza económica del periodo de altos precios ya estaba mostrando un franco proceso de agotamiento. A pesar de la recuperación de los precios en 2009, los

15 La acumulación de activos gubernamentales en el exterior debido a las transferencias de recursos al Fonden, también contribuyó a la generación de déficits de la cuenta capital de la balanza de pagos.

16 Mercal es una red de comercialización creada por el gobierno nacional con la finalidad de vender productos alimenticios a precios subsidiados.

17 La inflación a nivel de consumidor en el Área Metropolitana de Caracas pasó de 14.4\% en 2005 a $17 \%$ en 2006, a $22.5 \%$ en 2007 y a $31.9 \%$ en 2008 .

18 Después de que el 11 de julio de 2008 los precios petroleros alcanzaron su máximo nivel histórico (US\$/b 147,27 para el WTI), los mismos experimentaron una sostenida e intensa caída en los meses subsiguientes, llegando el barril del wTI a cotizarse por debajo de los us $\$ / \mathrm{b} 40$ a fines de ese año. El precio promedio de la cesta venezolana, por su parte, alcanzó los us $\$ / b$ 129 por barril a mediados de julio, mientras que en diciembre de 2008 llegó a us $\$ / b 31$. 
ingresos por exportación de ese año fueron sustancialmente menores que los del año precedente, pues el precio promedio (us $\$ 57,01$ por barril) fue muy inferior al del 2008 (us\$ 86,49). Eso no sólo implicó una aguda merma en la captación de divisas, sino también una importante caída de los ingresos fiscales, haciendo inevitable, por una parte, la restricción al acceso de divisas preferenciales altamente subsidiadas y, por la otra, un recorte fiscal de importancia.

Los importadores se vieron forzados a migrar al mercado cambiario libre para obtener las divisas que requerían, pero a un precio sustancialmente mayor, lo cual implicó una devaluación de facto del bolívar, ya que el tipo de cambio promedio de 2009 fue muy superior al del año precedente. Esa situación generó presiones inflacionarias de importancia, haciendo que el poder de compra de la población se redujera en más de 5\% en 2009 y que el consumo privado experimentara una fuerte contracción. Por su parte, la restricción fiscal hizo que el gasto público real no sólo dejara de crecer sino que disminuyera en magnitudes de importancia, y que las necesidades de financiamiento del gobierno crecieran sustancialmente. Adicionalmente, la inversión privada se redujo abruptamente en respuesta al acoso gubernamental creciente a la empresa privada.

La contracción de la demanda agregada interna resultante hizo que la actividad productiva experimentara una caída de importancia en 2009, que se vio agravada por la incapacidad cada vez más manifiesta del sector público para manejar las empresas estatalizadas, y las crecientes limitaciones de Pdvsa para mantener los volúmenes de producción y exportación y honrar sus compromisos con proveedores y contratistas.

En 2010 se repitió el adverso cuadro económico de 2009 con una contracción del PIB de $1.9 \%$ y una inflación de $27.2 \%$, superior a la del año precedente. Esto se debió a una serie de hechos, tales como: una devaluación implantada desde comienzos de enero de $2010 ;{ }^{19}$ los retrasos en la aprobación de divisas preferenciales por parte de Cadivi; la ilegalización del mercado cambiario libre a partir de mayo y su sustitución por el Sitme, mecanismo de adquisición limitada de divisas controlado por el BCV; y el agravamiento de las restricciones en la

19 El 8 de enero de 2010 se anunció un ajuste del tipo de cambio oficial de BsF/\$ 2,15, vigente desde el 3 de marzo de 2005, estableciéndose dos nuevas tasas preferenciales, una a $\mathrm{BsF} / \$$ 2,60 y otra a $\mathrm{BsF} / \$ 4,30$, llamándose a esta última el tipo de cambio petrolero, ya que se aplicará al grueso de la venta de divisas de Pdvsa al BCv. Por su parte, al instituto emisor se le asignó la nueva responsabilidad de participar activamente en el mercado cambiario libre, donde se transa un importante porcentaje de los dólares requeridos por el sector privado. Esto lo transforma en el principal oferente de divisas en ese mercado. 
prestación de servicios públicos, particularmente en materia eléctrica. La situación puede verse agravada, particularmente a mediano plazo, debido a la aplicación cada vez más radicalizada del modelo socialista, y al intento de solventar la deficiencia de ingresos petroleros y de fondos gubernamentales a través del financiamiento de gasto público por el BCV, ya que la aplicación de esta práctica de forma recurrente y creciente en el tiempo generaría presiones inflacionarias cada vez más intensas que a la larga resultarían difíciles y costosas de revertir.

\section{CONCLUSIÓN}

Las experiencias vividas durante las últimas décadas en la economía venezolana han demostrado una y otra vez que las bonanzas económicas generadas por las políticas procíclicas que se aplican en los periodos de altos precios petroleros son insostenibles. Éstas, que se caracterizan por intensos aumentos de la demanda, particularmente del consumo, son seguidas por situaciones de crisis que se presentan cuando los precios bajan, máxime si existen restricciones de producción petrolera. Al no contarse con recursos ahorrados durante los años de bonanza, la reducción abrupta de los ingresos tiene efectos devastadores, ya que la brecha es difícilmente cubierta con financiamiento, el cual, de estar disponible, es altamente costoso para una economía afectada por una caída abrupta de la renta de la que depende. De allí la importancia de crear fondos de estabilización macroeconómica con el ahorro de parte de la abundante renta obtenida durante los años de altas exportaciones, para así contar con recursos que les permitan paliar la caída de ingresos en los periodos de menores precios.

La frecuente presencia del fenómeno de la "enfermedad holandesa", característico del capitalismo rentístico, lleva eventualmente a la materialización del modelo de "transables no-transables", haciendo a estas economías altamente vulnerables a fenómenos externos fuera de su control. La pérdida de capacidad competitiva de los productores locales, generada por la prolongada y creciente sobrevaluación, eventualmente los lleva a cerrar sus plantas y a vender sus equipos, transformándose en importadores de lo que antes producían. Ello, además de limitar la inversión y la creación de puestos de trabajo, eleva la dependencia del suministro externo y aumenta la vulnerabilidad de la economía, ya que cuando sobrevienen los años de menores exportaciones y escasean las divisas, se limita la capacidad de importar, produciéndose escasez pues el aparato productivo no puede sustituir las importaciones con producción local. Esto causa presiones inflacionarias que se ven agravadas por las intensas e inevitables devaluaciones, que generan situaciones muy críticas caracterizadas por recesión económica, masivas 
salidas netas de capital, menor inversión, mayor desempleo, y mermas del consumo debido a la caída del ingreso personal real.

Las economías rentistas no pueden experimentar un proceso de desarrollo sustentable, ya que al depender de actividades económicas cambiantes, como la exportación de un commodity, están sujetas a una serie de realidades internacionales cambiantes y fuera de su control que las hace vulnerables y riesgosas. Esto es particularmente cierto en el caso de economías rentistas que dependen de la exportación de productos cuyos precios son altamente volátiles, como es el caso del petróleo.

El camino para evitar esos riesgos y consecuencias es la implantación de políticas económicas realistas y sustentables que busquen la diversificación de la economía, minimizando así las consecuencias de cambios bruscos en sus precios de exportación. Eso no implica el abandono de la actividad que genera la renta de la que se depende; por el contrario, lo procedente es el desarrollo de la misma con el fin de obtener abundantes recursos que permitan avanzar en el objetivo de la diversificación.

Idealmente, esas políticas económicas deben formar parte de un plan de desarrollo integral y sustentable que también incluya lo social, lo político, lo ambiental, lo cultural, lo científico y lo tecnológico, y que se base en un acuerdo político-social que le dé una base sólida de permanencia y sustentabilidad. Sólo así podrán vencer estas economías su condición rentista, evitándole a la población las consecuencias tan adversas que la misma genera, y ofreciéndole las posibilidades de una vida mejor.

\section{REFERENCIAS}

Academia Nacional de Ciencias Económicas y Academia de Ciencias Políticas y Sociales, "Venezuela ante la crisis", en Nueva Economía, Año viI, núm. 30, Academia Nacional de Ciencias Económicas, Caracas, noviembre de 2009, pp. 169-178.

Baptista, Asdrubal, "Tiempos de mengua. Los años finales de una estructura económica”, en Cunill Grau, Pedro, Manuel F. Sierra, y otros, Venezuela Contemporánea 1974-1988, Fundación Eugenio Mendoza, Caracas, 1989, pp. 105-156.

, "El capitalismo rentístico. Elementos cuantitativos de la economía venezolana", en Cuadernos del Cendes, Año 22, núm. 60, septiembre-diciembre 2005, pp. 95-111.

, Bases Cuantitativas de la Economía Venezolana 1830-2008. Caracas: Artesano Editores, 2011. 
Barcia, José, Una aproximación al tipo de cambio real de equilibrio en Venezuela y sus determinantes fundamentales, Caracas, MetroEconómica, 1999.

Barrios, Armando, José María Casal y otros, Venezuela: un acuerdo para alcanzar el desarrollo, Caracas, Acuerdo Social, 2006.

Faraco, Francisco, "El sistema financiero venezolano", en Banco de Venezuela, En Venezuela, 1997-2007, Caracas, Banco de Venezuela, Grupo Santander, 2008, pp. 10-82.

Gabaldón, Arnoldo José, Desarrollo sustentable. La salida de América Latina, Caracas, Editorial Grijalbo, 2006.

García, Gustavo, Rafael Rodríguez, Silvia Salvato, Lecciones de la crisis bancaria de Venezuela, Caracas, Ediciones IESA, 1997.

Kelly, Janet y Pedro Agustín Palma, "The Syndrome of Economic Decline and the Quest for Change", en McCoy, Jennifer y Myers, David (eds.) The Unraveling of Representative Democracy in Venezuela, Baltimore, Johns Hopkins University Press, 2004, pp. 202-230.

Krivoy, Ruth, Colapso, la crisis bancaria venezolana de 1994, Caracas, Ediciones IESA, 2002.

Malavé Mata, Héctor, El petróleo, el bolivar y el fisco, Caracas, Monteávila Editores, 2000.

Maza Zavala, Domingo Felipe, La década crítica de la economía venezolana 1998-2007, Ensayos, Caracas, Los Libros de El Nacional, 2009.

MetroEconómica (varios) Reporte general, Caracas, MetroEconómica.

Palma, Pedro Agustín, "La economía venezolana en el periodo 1974-1988: ¿últimos años de una economía rentista?", en Cunill Grau, Pedro, Manuel F. Sierra y otros, Venezuela contemporánea 1974-1988, Caracas, Fundación Eugenio Mendoza, 1989, pp. 157-248.

"La economía venezolana en el quinquenio 1994-1998: de una crisis a otra", en Nueva Economía, Año viıI, núm. 12, Caracas, Academia Nacional de Ciencias Económicas, abril de 1999, pp. 97-158.

, "The Venezuelan Economy: Problems Ahead", en Latin Business Chronicle, Coral Gables, June 12, 2006.

"La política cambiaria en Venezuela", en Veinticinco años de pensamiento económico venezolano, Caracas, Academia Nacional de Ciencias Económicas, 2008, pp. 461-532.

Zambrano Sequín, Luis, Estructura e incidencia de la politica fiscal en Venezuela, Caracas, Universidad Católica Andrés Bello, 2010. 
